\title{
Wilms' Tumor-Aniridia Association: Segregation of Affected Chromosome in Somatic Cell Hybrids, Identification of Cell Surface Antigen Associated with Deleted Area, and Regional Mapping of c-Ha-ras-1 Oncogene, Insulin Gene, and Beta-Globin Gene
}

\author{
James H. Fisher,' York E. Miller, ${ }^{1}$ Robert S. Sparkes, ${ }^{2}$ J. Brownwyn Bateman, ${ }^{2}$ Kathryn A. \\ Kimmel, ${ }^{3}$ Thomas E. Carey, ${ }^{3}$ Timothy Rodell, ${ }^{1}$ Steven A. Shoemaker, ${ }^{1}$ and Charles H. Scoggin ${ }^{1}$

\begin{abstract}
'Eleanor Roosevelt Institute for Cancer Research (contribution number 427), Webb-Waring Lung Institute and Division of Pulmonary Sciences, Section on Human Genetics, Department of Medicine, University of Colorado Health Colorado 80262 Denver, ${ }^{2}$ Division of Medical Genetics, Departments of Medicine, Pediatrics, and Psychiatry, UCLA Center for the Health Sciences, Los Angeles, California 90024; and ${ }^{3}$ The Cancer Research Laboratory in the Department of Otorhinolaryngology and Department of Microbiology and Immunology, University of Michigan, Ann Arbor, Michigan 48109
\end{abstract}

Received 16 February 1984-Final 4 May 1984

\begin{abstract}
Fusion of an auxotrophic mutant hamster cell with the skin fibroblasts of a child with the Wilms' tumor-aniridia association produced clones which, on the one hand, contained the child's normal chromosome 11 and, on the other, the chromosome 11 with the $11 \mathrm{p} 13$ deletion associated with the syndrome. Both hybrids were positive for human LDH-A by enzymatic assay. Clones containing the normal human chromosome 11 were killed by a cytotoxic monoclonal antibody to a cell surface antigen previously mapped to the $11 \mathrm{pl} 3 \rightarrow$ 11 ter region of chromosome 11 . Clones with the abnormal 11 were not killed. Thus, we have produced hybrids from the same patient distinct from each other on the basis of their chromosome 11. These hybrids have been used to map the locus for a cell surface antigen to the deleted region on chromosome 11 of a patient with the Wilms tumor-aniridia association. The linkage between this antigen and the syndrome should be helpful in further study of the genetics of this disease. In addition, we have found that the c-Ha-ras-1 oncogene is distal to the pl3 region of chromosome 11 and the position of insulin and beta-globin on the chromosome. Finally, by producing segregants of the hybrids containing the abnormal chromosome 11, we have provided evidence that chromosome 11-associated c-Ha-ras-1 is syntenic with chromosome 11 and not moved to a different portion of the genome.
\end{abstract}

\section{INTRODUCTION}

The aniridia-Wilms' tumor association (AWTA) is a rare disorder of childhood, conferring on affected individuals ambiguous genitalia, aniridia, and mental retardation in addition to an elevated risk for development of Wilms' tumor of the kidney (1). Recently, unrelated affected individuals have been shown to share a common haploid interstitial deletion of the p13 band of the short arm of chromosome 11 (1). It is speculated that the genes influenced by this deletion play an important role in the pathogenesis of the birth defects and the neoplasia associated with AWTA. 
As a first step in understanding the nature of the genes altered in AWTA, we have sought to isolate the normal and the affected human chromosome 11 from a patient. The present investigation demonstrates construction of two types of somatic cell hybrids-one with a AWTA patient's normal chromosome 11 and a second with her abnormal chromosome. We have utilized this constitutional difference of the hybrids to identify a cell surface antigen whose expression is determined by the region of the short arm of chromosome 11 deleted in the patient's abnormal chromosome. Additionally, we have used this hybrid system to determine the position of c-Ha-ras-1 oncogene on chromosome 11. By probing a hybrid with an $11 \mathrm{p}$ translocation to a Chinese hamster chromosome, we have found evidence to support the regional localization of c-Ha-ras- 1 to the $p$ terminal portion of chromosome 11. Finally, it appears that insulin and beta-globin are proximal to cHa-ras-1 on chromosome 11.

\section{MATERIALS AND METHODS}

Cell Lines and Cell Culture. The following cell lines were utilized: a human skin fibroblast from a 4-year-old patient with AWTA and a 11p13-p15.1 haploid deletion of chromosome 11 (Fig. 1); $\mathrm{Gly}^{-} \mathrm{A}$, an auxotrophic mutant hamster cell previously described (2); HeLa human tumor cell; HT 1080 human tumor cell (fibrosarcoma); CHO-K1 Chinese hamster ovary cell; J-1 human-hamster hybrid containing chromosome 11 as its only identifiable human genetic material (3); and $\mathrm{J}-11$ containing the short arm, centromere, and small portion of the long arm of chromosome 11 (3). Human cells were cultivated in medium F12 and $15 \%$ fetal calf serum and the hamster and hybrid cells in medium F12 and $8 \%$ fetal calf serum.

Cell Fusion. Gly ${ }^{-} \mathrm{A}$ hamster cells and fibroblasts from the patient were mixed in the presence of inactivated Sendai virus. The resulting hybrids were grown in glycine-
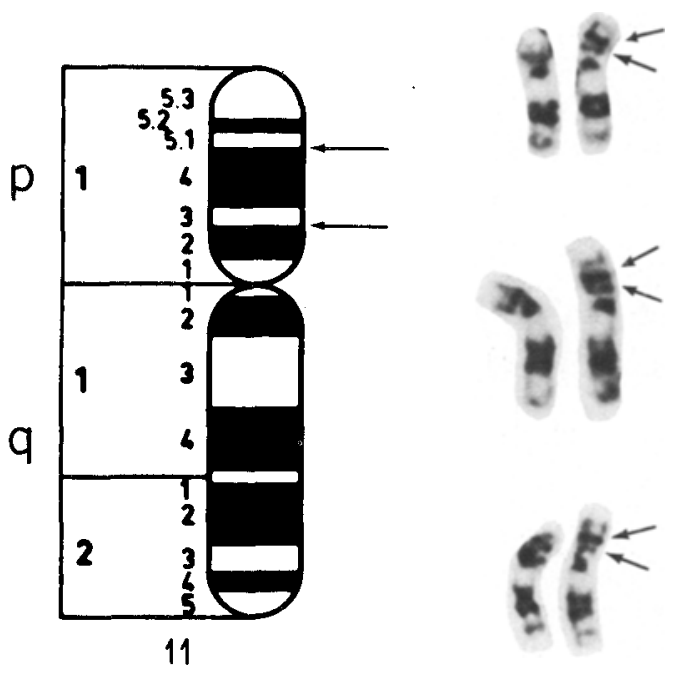

Fig. 1. Shown on the right side of the figure are three pairs of chromosome 11 from the patient with AWTA studied with $G$ banding. The deleted member is on the left side and the normal member on the right. On the left side is a diagram of a normal chromosome 11. The arrows indicate our best estimate of the break points of the deleted chromosome. An alternative interpretation is that the breaks have occurred in bands p12 and p14 and that the remaining dark staining band represents a fusion of the two bands.

deficient media containing $10^{-6} \mathrm{M}$ ouabain, which selects against growth of the parent hamster cell (glycine deficiency) and the human fibroblast (ouabain). Under these conditions, chromosome 12 is selected for, and chromosome 11 segregates with chromosome 12 in greater than $80 \%$ of hybrids (unpublished observation).

Hybrid Analysis. Single-cell plating was utilized to generate individual hybrid clones of uniform chromosomal construction. Hybrids were initially screened for the presence of chromosome 11 by enzymatic determination of LDH-A utilizing electrophoretic analysis (4). Clones which were LDH-A positive were then transferred to F12 and $8 \%$ fetal calf serum and repeatedly passed for 3-6 months to encourage segreation of human chromosomes. At the end of this time, cells were recloned by single-cell plating and retested for LDH-A. Those clones that were still positive for this enzyme were then sub- 
jected to cytogenetic analysis using trypsin banding and Giemsa-11 staining (5). At least 25 separate cells from each clone were cytogenetically analyzed. Additionally, the presence of the short arm of human chromosome 11 was assessed in the hybrids by the use of high-stringency molecular hybridization analysis utilizing probes derived from the short arm of chromosome 11 (6).

Monoclonal Antibody Utilized and Antigen Assay. E7 is an IgM monoclonal anti-. body raised against a squamous cell carcinoma of the upper respiratory system (7). Utilizing a deletion mutant panel of chromosome 11 , it has been demonstrated that the antigen maps to the $11 \mathrm{p} 13 \longrightarrow 11$ pter region of chromosome 11 , and by means of nutrient and glycolipid conversion analysis, it has been shown that the monoclonal antibody recognizes the antigen activity previously designated $a_{1}(8)$ [also referred to as "SA 11-1" and "S," $\left.S_{1}(9)\right]$. Cells were plated in the presence of complement (1.5\% normal rabbit serum) in increasing concentrations of hybridoma supernatant. After six days the plates were fixed, stained, and the number of colonies counted to determine survival.

Production of Segregant Hybrids. Segregants from the hybrids containing either a normal chromosome 11 or the abnormal chromosome were selected by growing the hybrids in the presence of complement and a monoclonal antibody which recognizes a cell surface antigen determined by the portion of the short arm of chromosome 11 outside of the patient's $11 \mathrm{p} 13$ deletion. This antibody was the gift of Dr. Carol Jones. The monoclonal antibody was generated from the $\mathrm{J} 11$ hybrid and appears to recognize only a chromosome 11 -associated antigen. Clones which grew in the presence of both complement and the antibody were isolated with cloning rings and harvested into $35-\mathrm{mm}$ tissue culture dishes containing media $\mathrm{F} 12$ plus $8 \%$ fetal calf serum, expanded, and analyzed for the presence of the chromosome 11-associated enzyme LDH-A. All LDH-A-negative cells were subjected to cytogenetic analysis to verify the absence of human chromosome 11 .

DNA and Southern Blot Analysis. DNA from Chinese hamster and hybrid cell lines was prepared in a standard manner by cell lysis, proteinase $\mathrm{K}$ digestion, sequential extraction with phenol and chloroform, and ethanol precipitation. Ten micrograms of DNA was digested with 60 units EcoRI under conditions recommended by the supplier (New England Biolabs). Fragments were separated by electrophoresis through a $0.8 \%$ agarose gel. The DNA was denatured and transferred to nitrocellulose by the method of Southern (10). Presence of hybridizable DNA and DNA transfer was verified by ethidium bromide staining of the gels after blotting. Hybridization and autoradiography were performed according to Wahl et al. (11). Highstringency analysis for the presence of DNA segments associated with the presence of the short arm of human chromosome 11 was performed by the above method with the exception that temperature of hybridization was increased to $55^{\circ} \mathrm{C}(6)$.

Probes for Hybridization. A recombinant pBR322 plasmid containing a $6.4-\mathrm{kb}$ human homolog of the c-Ha-ras- 1 oncogene (c-bas) was utilized for this study (12). This probe was the kind gift of Helen Romanczuk of Dr. Carlo Croce's laboratory. The c-Haras-1 DNA was utilized as a probe after labeling with $\left[{ }^{32} \mathrm{P}\right] \mathrm{dCTP}$ by nick translation (13). In each experiment $1 \times 10^{6} \mathrm{dpm} / \mathrm{ml}$ hybridization buffer of nick translated probe was used.

The recombinant plasmid utilized for insulin localization was $\mathrm{PH}$ ins 96 and was the kind gift of Graeme Bell of the Chiron Corporation. It contains a 1715 base pair (bp) insulin gene, $117 \mathrm{bp}$ of $3^{\prime}$ flanking sequence and $168 \mathrm{bp}$ of $5^{\prime}$ flanking sequence. This insulin probe was utilized after labeling with $\left[{ }^{32} \mathrm{P}\right] \mathrm{dCTP}$ by nick translation. In each experiment $1 \times 10^{6} \mathrm{dpm} / \mathrm{ml}$ hybridization buffer of nick translated probe was utilized. The probe for beta-globin was probe HB-IS derived from 
human beta-globin genomic clone $\lambda \mathrm{HBG}-1$ (14).

\section{RESULTS}

Hybrid Production and Characterization. After initial selection and subsequent growth in complete media, 14 of 20 initial clones were identified which were positive for human LDH-A, indicating the presence of human chromosome 11. Five clones, RTCHO-1-1, 5-1, 3-1, 21-2, and 24-2, were selected for cytogenetic analysis. Two of these clones contained a morphologically normal
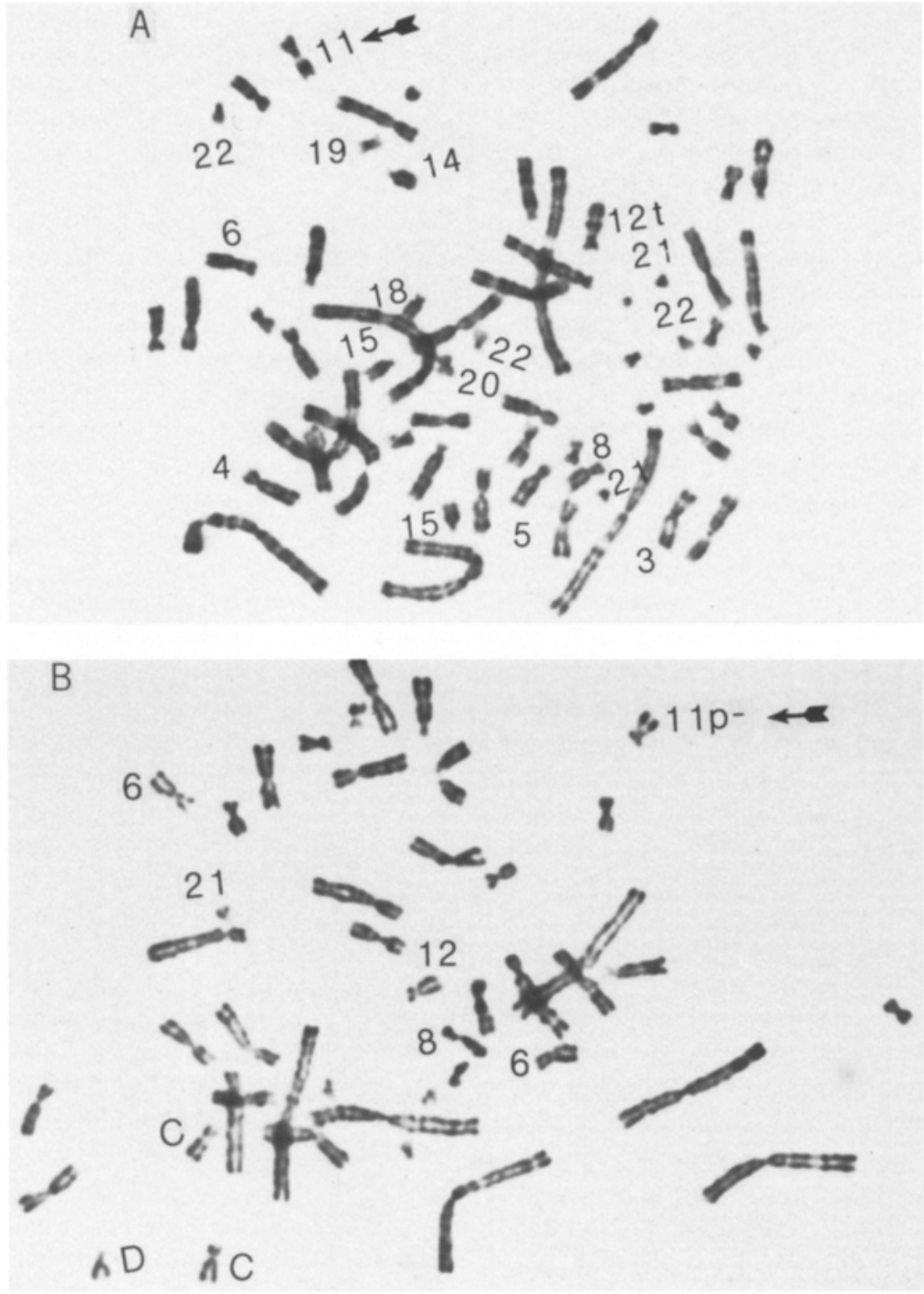

Fig. 2. Karyotypes of two hybrids: (A) RT-CHO-3-1 demonstrating a normal chromosome 11 and (B) RT-CHO-21-2 with the chromosome 11 containing the 11 p1300 $\rightarrow 15.1$ deletion. 
human chromosome 11 (Fig. 2A). Two clones had no identifiable normal human chromosome 11 , but rather a chromosome 11 which was identical to the patient's abnormal 11 with the p13 deletion (Fig. 2B). RT-CHO-1-1 contained a human chromosome 11 with a terminal $11 \mathrm{p}$ deletion and was translocated to a CHO chromosome (Fig. 3). The presence of human chromosome 11 was also confirmed by high-stringency molecular hybridization with DNA probes for the short arm of chromosome 11. Hybrids were found to be positive for such segments utilizing four separate DNA probes with different restriction patterns (data not shown). All five clones contained various other human chromosomes, including a normal chromosome 12.

Antigen Assay. The four clones cytogenetically characterized as having either a normal or abnormal chromosome 11 were subjected to cytotoxicity assay utilizing the $\operatorname{IgM}$ monoclonal antibody directed towards the antigen coded for by the $11 \mathrm{pl} \rightarrow$ ter region.

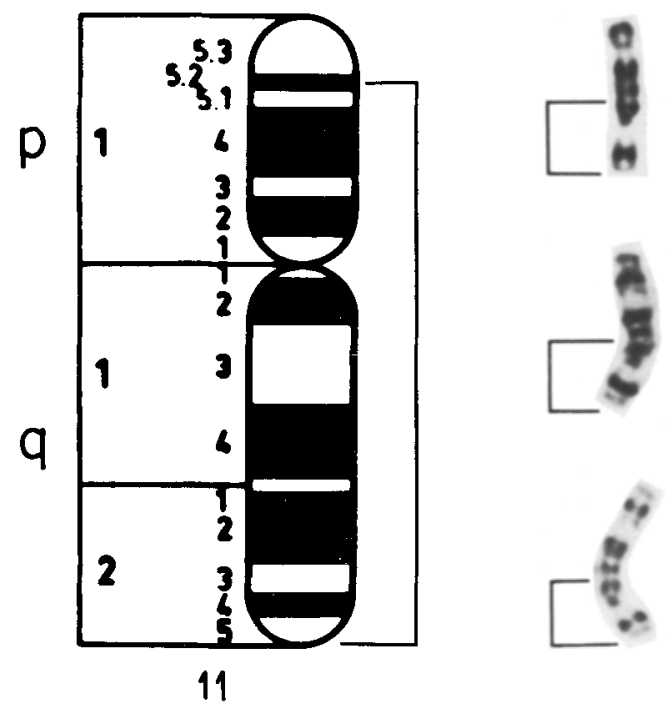

Fig. 3. Karyotype analysis of hybrid 1-1. Shown on the right are three representative chromosomes from three separate metaphase preparations demonstrating the chromosome 11 translocated to a Chinese hamster chromosome. Shown on the left is a diagram of a normal short arm of chromosome 11. The lower brackets denote the portion of chromosome 11 identifiable in the hybrid following translocation.
Both hybrids containing the normal chromosome 11 were killed by the antibody in the presence of complement, while those with the abnormal chromosome survived (Table 1). In addition, the continued presence of chromosome 11 was verified in the surviving cells by karyotyping, and hybrids were found to contain the abnormal chromosome 11 . Sensitivity of four additional cell lines was assessed. Two human transformed cell lines were killed by the antibody, as was a human-hamster hybrid containing a cytogenetically normal chromosome 11 as its only identifiable human genetic

Table 1. Percent Survival in Presence of Monoclonal Antibody against $\mathrm{a}_{1}$ Cell Surface Antigen ${ }^{a}$

\begin{tabular}{lrrrrr}
\hline & \multicolumn{5}{c}{$\begin{array}{c}\text { Survival (\%) at concentration of } \\
\text { hybridoma supernatant (ml } \\
\text { supernatant } / \mathrm{ml} \text { media) }\end{array}$} \\
\cline { 2 - 6 } Cell line & \multicolumn{1}{c}{$10^{-6}$} & $10^{-5}$ & $10^{-4}$ & $10^{-3}$ \\
\hline RT-CHO-1-1 & 100 & 87 & 2 & 3 & 0 \\
RT-CHO-5-1 & 100 & 100 & 1 & 0 & 0 \\
RT-CHO-3-1 & 100 & 100 & 2 & 0 & 0 \\
RT-CHO-21-2 & 100 & 94 & 96 & 87 & 78 \\
RT-CHO-24-2 & 100 & 95 & 83 & 97 & 93 \\
HeLa & 100 & 100 & 1 & 1 & 2 \\
HT 1080 & 100 & 2 & 2 & 0 & 2 \\
CHO-K1 & 100 & 100 & 100 & 100 & 100 \\
J-1 & 100 & 0 & 0 & 0 & 0 \\
\hline
\end{tabular}

${ }^{a}$ Values for survival of cell lines in the presence of complement and antibody represent percent cells surviving as compared to control cells untreated with antibody. The monoclonal antibody utilized is designated E7 and is an $\mathrm{IgM}$ monocional antibody raised against a squamous cell carcinoma of the upper respiratory system (4). Cells were plated in the presence of complement $(1.5 \%$ normal rabbit serum) in increasing concentrations of hybridoma supernatant. After six days, the plates were fixed and stained and the number of colonies determined. RT-CHO-1-1: human-hamster hybrid with chromosome 11 translocated to Chinese hamster chromosome and deletion of terminal portion of short arm of chromosome 11; RT-CHO-5-1: human-hamster hybrid containing normal chromosome 11; RT-CHO-3-1: human-hamster hybrid containing normal chromosome 11; RT-CHO-21-2: human-hamster hybrid containing chromosome 11 with (del 11) (p12 $\rightarrow$ pl5.1); RTCHO-24-2: human-hamster hybrid containing chromosome 11 with (del 11) (p12 $\rightarrow$ pl5.1); HeLa: human tumor cell; HT1080: human tumor cell (fibrosarcoma); CHO-K1: Chinese hamster ovary cell; J-1: humanhamster hybrid containing human chromosome 11 as its only identifiable nonhamster genetic material (10). 
material. The CHO-K1 hamster cell demonstrated no such sensitivity.

Demonstration of c-Ha-ras-1 Presence in Somatic Cell Hybrids with Normal Chromosome 11 or Chromosome with 11 pl 3 Deletion. Although each particular clone was grown from a single cell, to absolutely assure that a subpopulation of hybrids containing an intact chromosome $11 \mathrm{p}$ was not present in the population containing the abnormal chromosome 11 , the clones containing the abnormal chromosome 11 were grown in the presence of the E7 antibody and complement. This excluded any populations containing a normal $11 \mathrm{p}$. Following this, DNA was prepared for hybridization with c-Ha-ras-1, insulin, and beta-globin. Genomic DNA from hybrids containing either a normal human chromosome 11 or a human chromosome 11 with the 11 p 13 deletion was restricted with EcoR 1 and subjected to Southern analysis using c-Ha-ras-1 as a probe (Fig. 4). Utilizing EcoR1 restriction, the chromosome 11 human homolog of c-Ha-ras- 1 appears as a band at $27 \mathrm{~kb}$ while the Chinese hamster band is seen at $24 \mathrm{~kb}$ (data not shown). Two identical bands were observed in either cell: one of $27 \mathrm{~kb}$ corresponding to the chromosome 11-related homo$\log$ and one of $24 \mathrm{~kb}$ corresponding to the $\mathrm{CHO}$ homolog.

Demonstration of Chromosome 11Associated c-Ha-ras-l Segregation with Chromosome 11. Since all the hybrids studied contain other human chromosomes in addition to chromosome 11 , it was not possible to state with certainty that DNA containing the chromosome 11-related c-Ha-ras-1 sequence had not been translocated to another location. To examine this possibility, segregants were prepared from hybrids containing either the normal or abnormal chromosome 11. DNA from segregant clones were restricted with EcoR1 and then probed for c-Ha-ras-1. As can be seen in Fig. 5, the human chromosome 11-associated c-Ha-ras-1 band was not present in Southern blots of these segregants.

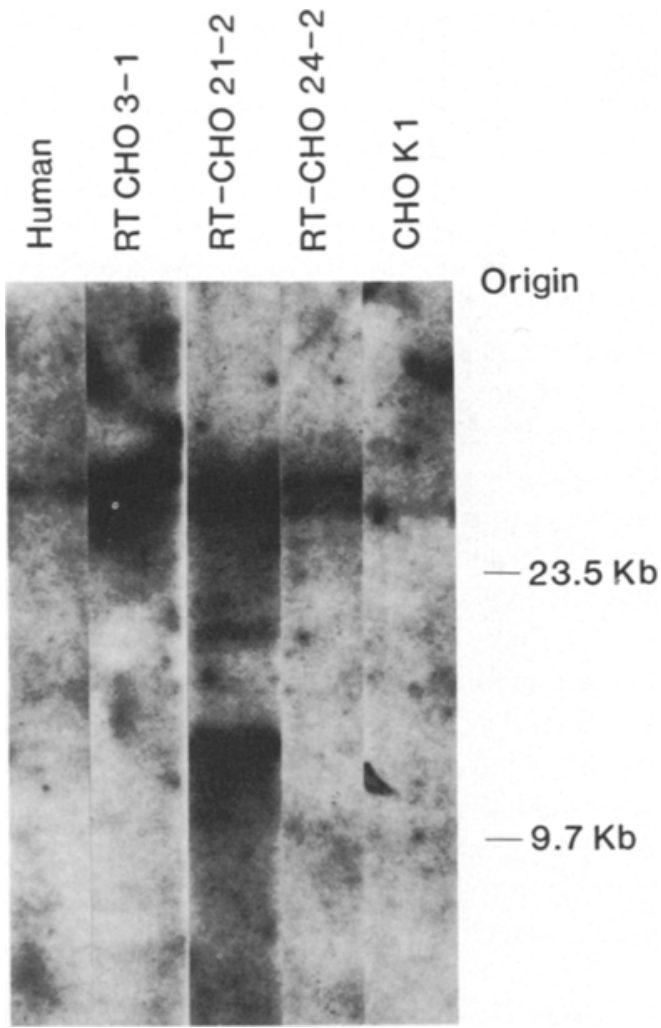

Fig. 4. Demonstration that c-Ha-ras- 1 is present in somatic cell hybrids containing either the patient's normal chromosome 11 or chromosome 11 with an $11 \mathrm{p} 1300$ 15.1 deletion. RT-CHO-3-1 contains the patient's normal chromosome 11 while hybrids RT-CHO-21-2 and RTCHO-24-2 contain the deleted chromosome. Ten micrograms of DNA from each hybrid was digested with EcoR1 loaded into each well probed with c-Ha-ras-1. Exposure time was 14 days.

Regional Mapping of Chromosome 11Associated c-Ha-ras-1. While use of the hybrids containing either a normal chromosome 11 or the chromosome 11 with the $11 \mathrm{p} 13$ deletion demonstrated that c-Ha-ras-1 apparentiy was located outside of the deletion, it was not clear if c-Ha-ras-1 was proximal or distal to the deletion. One human-hamster hybrid, RT-CHO-1-1, contained a human chromosome 11 with a translocation of the short arm of the chromosome 11 to a Chinese hamster chromosome with no $11 \mathrm{p} 13$ deletion (Fig. 3). In the course of this translocation, the terminal portion of the short arm was lost. 


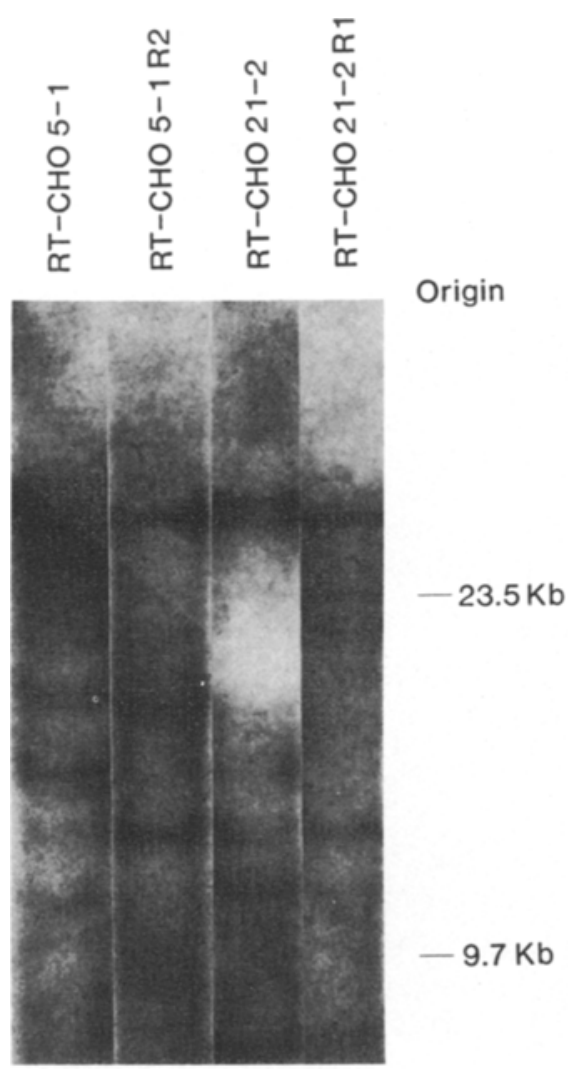

Fig. 5. To determine if c-Ha-ras-1 segregates with chromosome $11,10 \mu \mathrm{g}$ of DNA from segregants of the hybrids containing either the patient's normal chromosome 11 or deleted chromosomes were probed with c-Ha-ras-1. RTCHO-5-1 containing the normal chromosome 11 and RT-CHO-21-2 containing the chromosome 11 with the 11 pl $3 \rightarrow$ pl5.1 deletion have chromosome 11 -associated c-Ha-ras-1 while their chromosome 11 segregants RTCHO-5-1R2 and RT-CHO-21-2R1 do not.

When DNA from this hybrid was probed with $\mathrm{c}-\mathrm{Ha}-$ ras-1, the 27-kb band corresponding to chromosome 11-associated c-Ha-ras-1 was absent (Fig. 6). However, the 24-kb CHO homolog was present. These data are consistent with a regional location of $\mathrm{c}-\mathrm{Ha}$-ras- 1 to the distal portion of the short arm of chromosome 11.

Mapping of Genes for Insulin and BetaGlobin on Chromosome 11 Relative to $\mathrm{c}^{-}$ Ha-ras-1. DNA from hybrid cells containing a normal chromosome 11 , chromosome 11 with the p13-p15.1 deletion, segregants, and

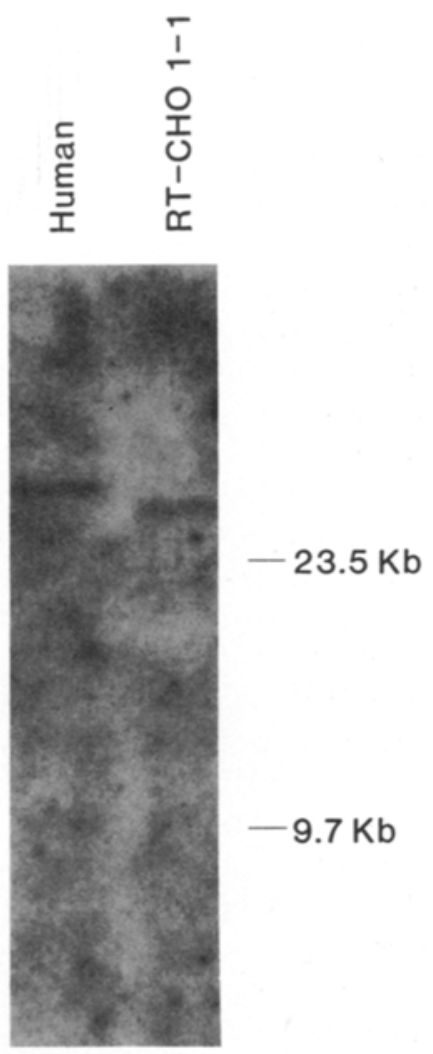

Fig. 6. Southern analysis of $10 \mu \mathrm{g}$ of EcoR 1 digested DNA from hybrid 1-1 using c-Ha-ras 1 probe. The $27-\mathrm{kb}$ band corresponding to chromosome 11 -associated $\mathrm{c}-\mathrm{Ha}$ ras- 1 is absent; however, the 24-kb Chinese hamster homolog is present. This is consistent with a regional localization of $\mathrm{c}-\mathrm{Ha}$-ras-1 distal to 11 p 15.2.

hybrids with only the short arm of chromosome 11 were probed with gene sequences for human insulin and beta-globin. Hybridization was seen with both insulin (Fig. 7) and betaglobin (Fig. 8), regardless of whether a normal chromosome 11 or one with an $11 \mathrm{pl} 3$ deletion was present. Additionally, hybridization was also detectable with DNA from the cell RT-CHO-1-1 which contained a deletion of the terminal portion of the short arm of chromosome 11. As mentioned previously, the chromosome 11-associated homolog of the c-Ha-ras-1 oncogene could not be detected in this hybrid. We feel these findings of DNA hybridization with the probes for insulin and beta-globin with this hybrid are consistent 


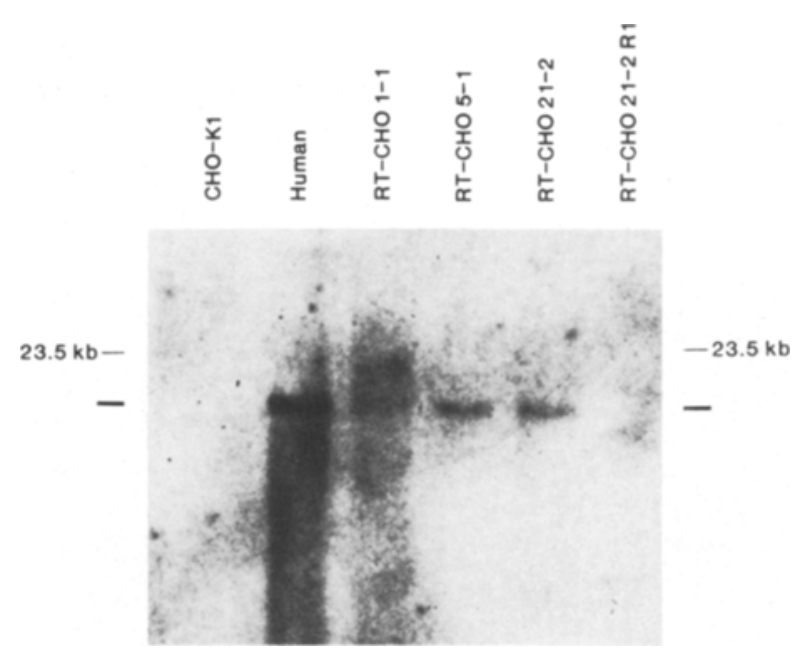

Fig. 7. Hybridization of human and hybrid EcoR1-digested DNA with DNA probe for human insulin gene. Hybridization was seen with human and hybrid DNA regardless of whether or not the patient's abnormal or normal chromosome 11 was present. In addition, hybridization was seen with DNA from the hybrid CHO-RT-1-1 with a terminal deletion of the short arm of chromosome 11. Ten micrograms of DNA was loaded into each well. Exposure time was 11 days.

with their location being proximal to the cHa-ras-1 oncogene.

\section{DISCUSSION}

These results show that somatic cell hybrids can be used to isolate particular human chromosomes containing a specific disease-associated abnormality. This approach allows the production of separate hybrids containing the patient's normal or abnormal chromosome. The production of these two distinct types of hybrids allows direct comparison of properties of the normal and the abnormal chromosomes. This probably represents a more searching comparison than that of the patient's affected chromosome with a similar chromosome in hybrids constructed from the cells of other individuals, because they have the same replicative history and environment prior to fusion with hamster cells.

We have utilized these two types of hybrids to explore the expression of a cell surface antigen which has been regionally mapped to the short arm of chromosome 11 . Hybrids containing the normal chromosome
11 were killed in the presence of a monoclonal antibody to this antigen, while the hybrids with the chromosome 11 containing the 11 p 13 deletion were not. This result constitutes evidence that the expression of the antigen maps to the deleted region. It must be emphasized that the deletion of the chromosome 11 studied is relatively large, so the exact position of the E7 antigen and its relationship to the lesion responsible for AWTA remains to be more precisely delineated. Further investigations of this linkage in several patients with a variety of such deletions should be illuminating.

The availability of this hybrid system allows additional investigations of human chromosome 11. By using somatic cell hybridization and Southern analysis of hybrids produced from a patient with an interstitial deletion in the short arm of chromosome 11, we have observed that hybrid cell lines prepared from a patient with AWTA association, which contain either a normal chromosome 11 or an abnormal chromosome 11, display identical hybridization when subjected to Southern analysis using c-Ha-ras-1 as a probe. Thus, c-Ha-ras-1 does not appear to be in the de- 


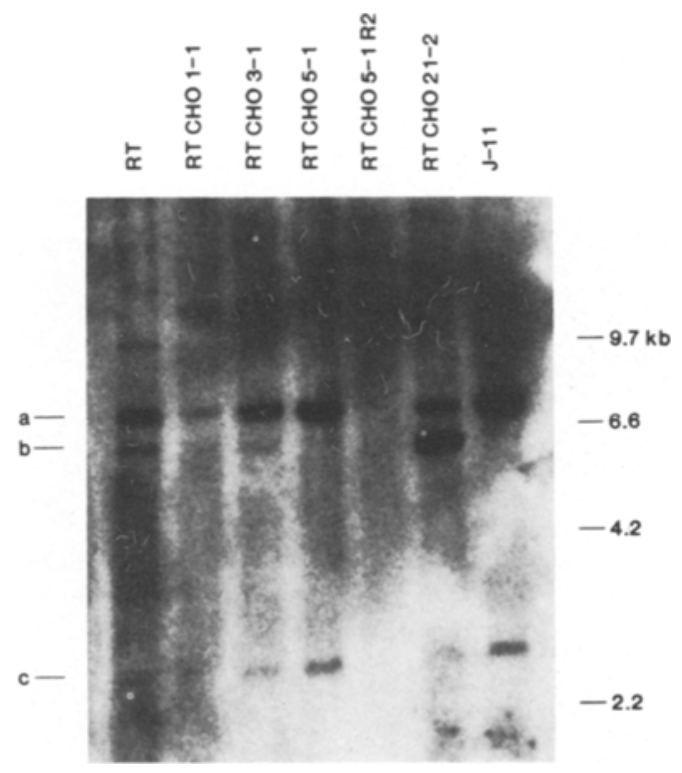

Fig. 8. Hybridization of human beta-globin probe to 10 $\mu \mathrm{g}$ EcoR1-digested DNA from patient's fibroblasts and hybrid cells. Major regions of hybridization are shown by markers a and $c$. Band at marker $b$ and at high molecular weight in hybrid CHO-RT-1-1 and -3-1 were known to represent plasmid contamination by probing of samples with ${ }^{32} \mathrm{P}$-labeled $\mathrm{pBR} 322$. The pattern of hybridization of beta-globin with both human and hybrid EcoR 1-digested DNA is consistent with previous reports from this institute (3). Hybridization was seen with DNA from hybrids containing the normal or abnormal chromosome 11 and the hybrid RT-CHO-1-1 with a terminal deletion of the short arm of chromosome 11.

leted area of chromosome 11 . This finding is in agreement with observations utilizing restriction site polymorphisms of c-Ha-ras-1 to examine cells containing both chromosome 11 from patients with AWTA $(15,16)$. Furthermore, utilizing a hybrid with a translocation of chromosome 11 to a Chinese hamster chromosome and subsequent loss of the $11 \mathrm{p}$ terminal portion and human c-Ha-ras-l homolog, we have regionally mapped the chromosome 11-associated c-Ha-ras-1 to the distal portion of chromosome 11 . This concurs with the assignment of c-Ha-ras-l to $11 \mathrm{p} 15.1 \rightarrow 11 \mathrm{p} 15.5$ by Huesse et al. (15).

Our findings by molecular hybridization of a distal location of c-Ha-ras-1 is in contrast to a previous assignment of c-Ha-ras-1 to 11 pl4.1 using in situ hybridization (17) of normal cells but agrees with the assignment of others using Southern analysis $(15,16)$. Assuming that precise localization of $\mathrm{c}-\mathrm{Ha}-$ ras- 1 is within the resolving power of both in situ hybridization and molecular hybridization of DNA from specific somatic cell hybrids, there are several explanations for the observed discrepancy.

It is possible that our and others' cytogenetic analysis is in error, although this seems unlikely. A second possibility is that the localization of c-Ha-ras-1 to 11 p14.1 is incorrect. A third explanation is that genes which appear to have been deleted from chromosome 11 in AWTA have been translocated to another chromosome or chromosomes. By isolating the abnormal chromosome and demonstrating that c-Ha-ras-l segregates with the chromosome, we have shown that c-Ha-ras-1 is still on the abnormal chromosome. The possibility that the abnormal chromosome has been internally rearranged has not been excluded; thus, a fourth explanation is that there may be abnormalities of the chromosomal structure of the abnormal chromosome 11 in AWTA which were not visible by cytogenetic analysis alone, such that c-Ha-ras-1, and possibly other genes, have been moved to a different position in the short arm of chromosome 11. If this explanation is correct, it is possible that $\mathrm{c}-\mathrm{Ha}$-ras-1 or associated genes are regulated in an abnormal manner at some stage of development in individuals who manifest the AWTA. These genes may be directly involved in either the genesis of Wilms' tumor or the other various abnormalities of the association such as ambiguous genitalia, aniridia, and mental retardation. This hypothesis could be examined by determining the precise location of c-Ha-ras- 1 in other normal individuals and in other somatic cell hybrids derived from the cells of patients with the deletion of chromosome 11, either with or without Wilms' tumor of the kidney.

The human insulin gene has been conclusively mapped to human chromosome 11; however, its regional location on the chromosome has been controversial. Harper et al. 
(18), utilizing in situ hybridization, have found evidence of localization of the gene to 11 p15, while Lebo et al. (19), utilizing a different approach involving cell sorting of cells with chromosomal translocations followed by restriction endonuclease analysis, have placed the insulin locus on or between 11 pl $1 \rightarrow$ p15. Owerbach et al. (20), utilizing a somatic cell hybrid with a translocation involving chromosomes 11 and $\mathrm{X}$, have placed the gene in the region $11 \mathrm{p} 13 \rightarrow$ pter. More recent studies, utilizing copy number analysis in patients with the interstitial deletion associated with AWTA, have supported a location of the insulin gene in the band $11 \mathrm{pl} 5$ (16). Our findings exclude the insulin gene from the p13 band, and the finding of insulin gene in the hybrid which had lost c-Ha-ras-1 argues against a proposed assignment of the insulin gene distal to c-Ha-ras-1 on chromosome 11 (21).

The beta-globin gene has been previously localized to the p1205-p1208 region using molecular hybridization of cloned beta-globin sequence with DNA from a well characterized chromosome 11 deletion mutant panel (3); however, de Martinville and Franche (16) have localized beta-globin distal to $11 \mathrm{p} 13$. Our data would support either location, but if beta-globin is distal to $11 \mathrm{p} 13$, it is proximal to c-Ha-ras and in close proximity to insulin. No statements can be made regarding the exact sequence of beta-globin and insulin on chromosome 11 using our data.

Finally, this approach utilizing somatic cell hybrids to compare a normal chromosome to an altered chromosome would appear to be useful in the study of other disease conditions involving specific chromosomal abnormalities.

\section{ACKNOWLEDGMENTS}

The authors wish to thank Dr. Helvise Morse for cytogenetic analysis provided for this study and Dr. Steven Funderburg for his assistance. This is contribution (No. 427) from the Eleanor Roosevelt Institute for Cancer Research. Supported by NIH grants HD 14567, CA 28564, CA00621, T32 GM 07544, HD 02080, Milheim Foundation project number 344098, and the Parker B. Francis Foundation.

\section{LITERATURE CITED}

1. Riccardi, V.M., Sujansky, E., Smith, A.C., and Francke, U. (1978). Pediatrics 61:604-607.

2. Kao, F.T., Jones, C., and Puck, T.T. (1975). Proc. Natl. Acad. Sci.U.S.A. 73:193-197.

3. Gusella, J., Varsanyi-Breiner, A., Kao, F.T., Jones, C., Puck, T.T., Keys, C., Orkin, S., and Housman, D. (1979). Proc. Natl. Acad. Sci. U.S.A. 76:52395243.

4. Preston, J.A., Briere, R.O., and Batskis, J.G. (1965). Am. J. Clin. Pathol. 43:256-260.

5. Morse, H.G., Patterson, D., Hays, T., and Robinson A. (1982). Hum. Genet. 61:141-144.

6. Fisher, J.H., Gusella, J., and Scoggin, C.H. (1984). Proc. Natl. Acad. Sci. U.S.A. 81:520-524.

7. Jones, C., Kimmel, K.A., Carey, T.E., Miller, Y.E., Lehman, D.W., and Mackenzie, D. (1983). Somat. Cell Genet. 9:489--496.

8. Jones, C., Kimmel, K., Carey, T., Miller, Y., Lehman, D., and Mackenzie, D. (1983). Somat. Cell Genet. 9:489-496.

9. Jones, C., Moore, E.E., and Lehman, D.W. (1979). Proc. Natl. Acad. Sci. U.S.A. 76:6491-6495.

10. Southern, E.M. (1975). J. Mol. Biol. 98:503-517.

11. Wahl, G.M., Stern, M., and Stark, G.R. (1979). Proc. Natl. Acad. Sci. U.S.A. 76:3683-3687.

12. Santos, E., Tronick, S.R., Aaronson, S.A., Pulciani, S., and Barbacid, M. (1982). Nature 298:343-347.

13. Rigby, P.W.S., Dieckmann, M., Rhodes, C., and Berev, P.J. (1977). Mol. Biol. 133:237-251.

14. Lawn, R.M., Efstradiadis, A., O'Connell, C., and Maniatis, T. (1980). Cell 21:647-651.

15. Huesse, C., Despoisse, S., Gilgenkrantz, S., Lenoir, G.M., and Junien, C. (1983). Nature 305:638-641.

16. deMartinville, B., and Francke, U. (1983). Nature 305:641-643.

17. Jhanwar, S.C., Neel, B.G., Hayward, W.S., and Chaganti, R.S.K. (1983). Proc. Natl. Acad. Sci. U.S.A. 76:6491-6495.

18. Harper, M.E., Ullrich, A., and Saunders, G.F. (1981). Proc. Natl. Acad. Sci. U.S.A. 78:44584460.

19. Lebo, R.V., Kan, Y.W., Cheung, M.C., Carrano, A.V., Loh-Chung, Y., Chang, J., Cordell, B., and Goodman, H.M. (1982). Hum. Genet. 60:10-15.

20. Owerbach, D., Bell, G.I., Rutter, W.J., Brown, J.A., and Shows, T.B. (1981). Diabetes 30:267-270.

21. Fearon, E.R., Antonarakis, S.E., Meyers, D., and Levine, M. (1983). Am. J. Human Genetics 36: Abstract 390 . 